\title{
PENEMPATAN POSISI MULTI KAMERA BERDASARKAN GAYA SUTRADARA BERBASIS LOGIKA FUZZY
}

\author{
Hartarto Junaedi ${ }^{13}$, Jaya Pranata ${ }^{3}$, Mochamad Hariadi ${ }^{12}$, I Ketut Eddy Purnama ${ }^{12}$ \\ ${ }^{1}$ Departemen Teknik Elektro, Fakultas Teknologi Elektro , Institut Teknologi Sepuluh Nopember Surabaya \\ ${ }^{2}$ Departemen Teknik Komputer, Fakultas Teknologi Elektro , Institut Teknologi Sepuluh Nopember Surabaya \\ ${ }^{3}$ Departemen Sistem Informasi , Sekolah Tinggi Teknik Surabaya \\ Email: hartarto12@mhs.ee.its.ac.id, seijuroshin21@gmail.com,mochar@ee.its.ac.id, ketut@ee.its.ac.id
}

(Naskah masuk: 12 Oktober 2018, diterima untuk diterbitkan: 06 November 2018)

\begin{abstract}
Abstrak
Teknologi komputer saat ini telah banyak digunakan dalam pengembangan animasi atau permainan komputer. Machinima sebagai salah satu teknologi komputer terbaru pada mesin grafik 3D untuk menghasilkan produk sinematik secara real time. Penempatan posisi kamera sangat memegang peranan penting dalam proses pembuatan produk sinematik. Penempatan posisi kamera ini tentu harus sesuai dengan kaidah-kaidah sinematografi. Penelitian ini akan mengusulkan sebuah pendekatan agen cerdas dengan multi perilaku untuk menempatkan kamera virtual dalam lingkungan virtual secara otomatis sesuai dengan gaya seorang sutradara. Setiap kamera virtual itu akan memiliki perilaku yang berbeda berdasarkan kaidah sinematografi sehingga memiliki Point of View (POV) yang berbeda. Untuk memberikan perilaku pada kamera virtual akan digunakan pendekatan berbasis logika fuzzy dengan menggunakan metode mamdani. Jumlah variabel masukan yang digunakan sejumlah tiga dan variabel keluaran sejumlah tiga dengan membership function antara tiga sampai lima. Penelitian ini akan menggunakan simulasi permainan komputer dengan tiga kamera virtual dengan perilaku yang berbeda untuk merekam adegan yang sama dan hasilnya akan divalidasi berdasarkan hasil pengamatan dengan komunitas juru foto. Pada akhirnya dapat diambil kesimpulan bahwa pendekatan logika fuzzy dapat digunakan untuk memberikan sebuah perilaku atau gaya sutradara pada kamera virtual.
\end{abstract}

Kata kunci: machinima, logika fuzzy, penempatan posisi kamera, multi kamera, gaya sutradara, mamdani

\section{MULTI CAMERA POSITIONING BEHAVIOR BASED ON DIRECTOR'S STYLE USING FUZZY LOGIC}

\begin{abstract}
Computer technology is has been used widely in the development of animation or computer games. One of the technologies is machinima, a system that uses reak time $3 D$ graphics engine technology to produce cinematic products. In the process of develop a cinematic product, camera positioning is a very important component. The camera positioning must be comply with cinematography's rule. This research will propose an intelligent multi agent behavior to positining a virtual camera in a virtual environment automatically according to the director's style. Each virtual camera will have a different behavior based on cinematographic rules so that it has a different Point of View (POV). To assign a behavior on the virtual camera will be based on fuzzy logic using the mamdani method. The number of input variables are three and the output variables are three with the number membership functions between three to five. This research will program a computer game simulation with three multi behavior virtual cameras to capture some scene and the results will be validated based on observations with the photographer community. Finally it can be concluded that the fuzzy logic approach can be used to assign some behavior to a virtual camera.
\end{abstract}

Keywords: machinima , fuzzy logic , camera positioning , multi behavior camera, director's style, mandani

\section{PENDAHULUAN}

Dalam beberapa tahun terakhir ini, pemanfaatan komputer di semua bidang industri telah berkembang sangat pesat, termasuk di bidang industri kreatif seperti pengembangan permainan komputer dan animasi. Pada saat ini teknologi grafik komputer sudah berpindah dari teknologi 2D menjadi 3D. Salah satu teknik yang sangat mendukung di bidang ini adalah machinima.

Machinima adalah suatu teknik pembuatan produk sinematik dalam lingkungan virtual secara 
real time (HANCOCK \& INGRAM,2007) Dengan menggunakan machinima, dapat dibuat sebuah lingkungan virtual dan semua karakter yang diinginkan. Dan pada lingkungan virtual ini dapat dianimasikan semua tindakan yang diinginkan seperti layak nya dunia nyata. Salah satu bagian yang penting dalam machinima adalah pengaturan posisi kamera, di mana posisi kamera seharusnya dan bagaimana cara kamera mengambil gambar.

Para pengembang aplikasi permainan komputer 3D memberikan perhatian secara khusus bagaimana suatu permainan dapat memberikan kesan dunia nyata di dalam sebuah lingkungan virtual. Para pengembang aplikasi 3D ini menggunakan beberapa metode dan algoritma untuk membuat semua detail komponen yang ada di lingkungan virtual sehingga mendekati dunia nyata dan senatural mungkin sehingga memberikan hasil yang bagus. Dunia virtual semakin dituntut sesuai dengan dunia real. Keterlibatan seorang sutradara makin dituntut dalam pembuatan permainan maupun animasi. Seorang sutradara sering kali memanfaatkan sebuah story board untuk menjelaskan ide yang diinginkan dalam produk sinematik tersebut sesuai dengan kaidah sinematografi (Hart 2007).

Saat membuat sebuah produk sinematik, biasanya penempatan posisi kamera dilakukan oleh seorang juru kamera atau animator. Tetapi penempatan posisi kamera virtual secara manual dalam lingkungan virtual membutuhkan banyak pemodelan dan penghitungan yang harus diulangi untuk setiap adegan. Tentu saja hal ini akan membutuhkan biaya dan waktu yang cukup tinggi (Ranon, Chittaro \& Buttusi 2015).

Film Avatar yang disutradarai oleh James Cameron merupakan tonggak dari kelahiran produksi film berbasis lingkungan virtual (Benneth dan Carter 2015). Untuk menciptakan film box office ini, dikembangkan sebuah teknologi kamera virtual untuk merekam apa yang diinginkan oleh James Cameron selaku sutradara. Kamera virtual ini memiliki kemampuan layaknya kamera biasa dan dioperasikan oleh juru kamera tetapi hanya dapat dipakai pada lingkungan virtual saja.

Banyak penelitian yang menggunakan sebuah bahasa penengah untuk mengontrol kamera virtual pada lingkungan virtual, sehingga kontrol kamera akan seperti pada lingkungan real (Hu dan Zhang 2012).

Sebuah sistem penempatan kamera telah dibuat, tetapi sistem tersebut hanya menempatkan posisi kamera kedua saja sedangkan kamera pertama selalu pada posisi statis yang sudah ditetapkan. Untuk memberikan perilaku dalam kamera tersebut digunakan metode static behavior tree (Prima, Java, Suryanto \& Hariadi 2013).

Pendekatan berbasis algoritma evolusioner juga digunakan dalam penelitian untuk penempatan posisi kamera. Algortima Particle Swarm Optimization (PSO) juga dapat digunakan untuk memberikan kecerdasan buatan kepada multi-agen dengan perilaku yang berbeda (Junaedi, Hariadi dan Ketut 2013). Permasalahan Virtual Camera Composition (VCC) juga diselesaikan dengan algoritma PSO. Perhitungan yang digunakan adalah posisi kamera, area atau orientasi kamera dan Field of View (FOV) yang direkam oleh kamera (Burelli, Gaspero, Ermetici dan Ranon 2008). Beberapa aturan dalam dunia fotografi telah berhasil diterapkan dengan menggunakan algoritma Multi Objective PSO seperti aturan rule of third, horizon line dan Point of Interest (POI) (Barry dan Ross 2014). Sedangkan permasalahan pengerakan kamera virtual yang agak kasar dapat dihaluskan dengan metode PSO dan regresi lokal. (Prima, Hariadi, Ketut Purnama dan Usagawa 2016). Pendekatan berbasis algoritma evolusioner tentu akan sulit digunakan untuk permainan real time karena waktu komputasi yang dibutuhkan.

Sebuah penelitian agen cerdas juga dibuat untuk melakukan navigasi otomatis dengan perilaku tertentu dalam mencari pintu keluar dan menghindari rintangan pada lingkungan virtual. Agen cerdas ini dibuat menggunakan pengontrol berbasis algoritma fuzzy (Jaafar dan McKenzie 2006).

Permainan komputer akan berbeda dengan sebuah produk sinematik semacam film dan animasi karena sifat real time dari permainan tersebut. Berbeda dengan film, sebuah adegan dapat diambil beberapa kali dan dapat juga berhenti sementara dan dilanjutkan lagi sesuai dengan kebutuhan dan kondisi di lapangan, sedangkan untuk permainan komputer penempatan posisi kamera ini harus secara real time juga (Nicolas, Ralf dan Thomas 2001).

Dalam pembuatan film, dibutuhkan beberapa kamera karena terkadang seorang sutradara perlu menekankan beberapa tindakan atau properti. Jika menggunakan satu kamera hanya memberikan satu sudut pandang. Setiap kamera diperlukan untuk mendapatkan sudut pandang yang berbeda.

Dari penelitian terdahulu ini terlihat bahwa penempatan posisi kamera secara otomatis sangat penting sekali. Salah satu hal terpenting dalam pembuatan permainan atau animasi adalah penempatan posisi kamera. Perbedaan posisi penempatan kamera virtual akan membawa nuansa yang berbeda. Dan terlihat bahwa belum ada penempatan posisi kamera virtual menggunakan pendekatan logika fuzzy. Beberapa pendekatan yang sudah dilakukan antara lain metode evolusioner dan machine learning. Pendekatan logika fuzzy tidak membutuhkan proses perhitungan berulang seperti metode swarm dan juga tidak membutuhkan pelatihan dengan menggunakan kumpulan data berlabel. Oleh karena itu penelitian ini akan dibuat dengan pendekatan berbasis logika fuzzy. Penelitian ini merupakah sub sistem dari sebuah sistem besar yang akan disebut ACE. Penelitian ini akan membuat beberapa kamera virtual dengan perilaku 
yang berbeda satu sama lain. Setiap kamera yang ada adalah kamera yang dinamis, yang posisinya akan berubah setiap sebuah aksi terjadi.

Sistematika pembahasan penelitian ini disusun dalam enam bagian sebagai berikut. Bagian pertama akan menyajikan pendahuluan mengenai machinima dan penelitian yang berkaitan dengan penempatan posisi kamera. Bagian kedua akan menjelaskan mengenai kaidah sinematografi dasar yang menjadi acuan atau dasar penelitian ini. Desain implementasi perilaku dengan menggunakan logika fuzzy dapat dilihat pada bagian ketiga. Pada bagian keempat adalah desain simulasi yang dirancang. Dalam bagian kelima akan disajikan hasil percobaan animasi untuk beberapa aksi adegan dan akhirnya pada bagian terakhir adalah kesimpulan dan usulan penelitian lanjut untuk masa depan makalah ini.

\section{SINEMATOGRAFI}

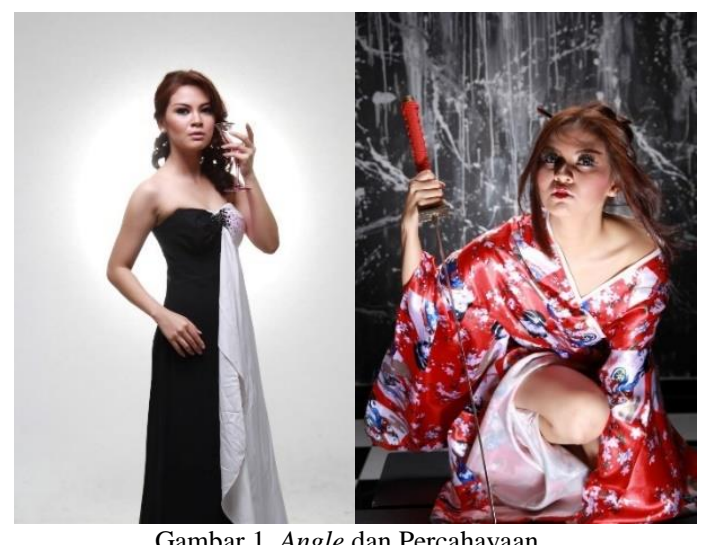

Sebuah film terdiri dari banyak pengambilan gambar. Tiap pengambilan gambar membutuhkan penempatan kamera pada posisi terbaik. Sinematografi berarti pengaturan cahaya dan peletakan kamera pada posisinya yang akan digunakan dalam merekam gambar foto untuk film (Marcelli 1965). Untuk dapat menghasilkan film yang bagus, terdapat beberapa faktor yang perlu dipertimbangkan. Dengan pengaturan letak kamera dan pencahayaan dapat membuat film menjadi lebih menarik dan sesuai dengan jalan cerita atau skenario yang telah dibuat. Sinematografi yang bagus akan sangat membantu penonton mengerti alur cerita yang diangkat dalam film tersebut.

Pada Gambar 1 terlihat 2 buah foto yang diambil dengan angle dan pencahayaan yang berbeda. Foto kiri diambil berdasarkan eye view level dan percahayaan dari atas. Sedangkan gambar kanan diambil dari low angle dan percahayaan dari bawah. Dengan angle dan pencahayaan efek foto akan berbeda, foto kiri tampak elegant dan anggun sedangkan foto sebelah kanan menunjukkan efek dunia underworld sesuai dengan tema fotonya. Efek yang sama juga tampak pada poster film man of steel.

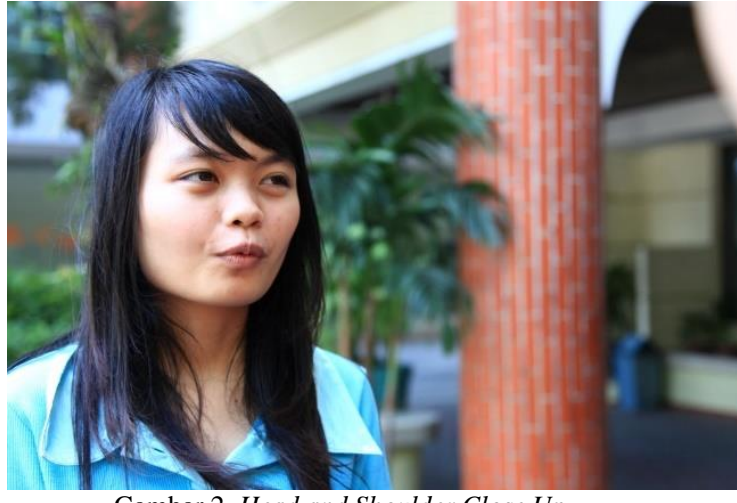

Gambar 2. Head and Shoulder Close Up

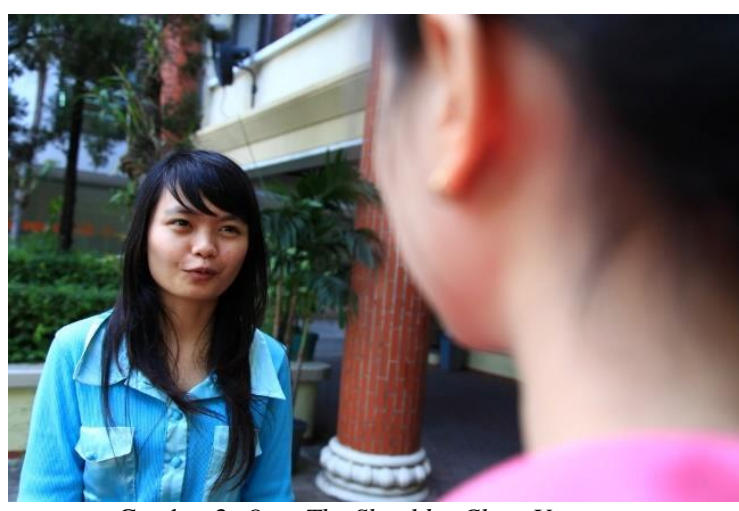

Gambar 3. Over The Shoulder Close Up

Terdapat beberapa faktor yang perlu dipertimbangkan untuk menghasilkan film yang bagus yaitu:

- Camera Angle

Camera angle adalah suatu lokasi spesifik dari sebuah kamera ketika melakukan pengambilan gambar pada sebuah adegan (Arijon 1976). Camera angle adalah sudut pandang yang disimpan oleh kamera. Sebuah adegan dapat diambil dari beberapa variasi sudut untuk mendapatkan kesan yang berbeda dari penonton. Ada beberapa jenis camera angle seperti objective shot, subjective shot dan point of view shot. Pengambilan gambar ini dapat dibagi lagi menjadi close up shot, medium shot dan long shot

- Continuity

Continuity adalah kesinambungan suatu adegan dengan adegan yang lainnya. Sebuah film dengan continuity yang bagus dapat menceritakan sebuah kejadian dengan lebih realistik. Sebaliknya sebuah film dengan continuity yang tidak tepat dapat membuat sebuah film menjadi tidak menarik. Namun hal ini tidak berarti bahwa setiap potongan adegan dalam film harus memiliki continuity.

- Cutting

Cutting adalah proses mengubah sudut pandang kamera (Brown 2012). Cutting adalah suatu proses penting dalam 
pembuatan film karena memegang peranan penting untuk membangun plot dari sebuah cerita. Tanpa adanya proses cutting yang benar, plot dari sebuah film akan menjadi kacau.

- $\quad$ Close Up

Close up adalah proses pengambilan gambar dengan jarak yang sangat dekat dengan aktor untuk mendapatkan ekspresi dari actor tersebut atau menekankan sebuah properti. Terdapat beberapa variasi dari close up shot seperti:

- Medium close up

Pengambilan gambar dari sekitar pertengahan pinggang dan bahu sampai atas kepala.

- Head and shoulder close up

Gambar 2 adalah pengambilan gambar berdasarkan variasi head and shoulder close up. Pengambilan gambar di area bawah bahu sampai atas kepala.

- Head close up

Hanya bagian kepala saja yang diambil gambar

- Choker close up

Pengambilan gambar yang befokus pada bibir sampai atas mata

- Extreme Close up

Pengambilan gambar pada sebagian area objek benda, di mana pengambilan gambarnya sangat dekat dengan objek tersebut sehingga objek tersebut akan tampak sangat besar di layar.

- Over the shoulder close up

Gambar 3 adalah contoh pengambilan gambar berdasarkan over the shoulder. Teknik ini merupakan teknik dalam dunia fotografi yang paling sering digunakan, yaitu pengambilan gambar dekat dengan aktor dan posisi kamera sejajar dengan bahu aktor tersebut di depan latar belakang.

\section{- Composition}

Suatu composition dikatakan baik apabila susunan elemen bergambar membentuk satu kesatuan yang utuh dan harmonis. Kompisisi adalah tentang bagaimana seorang sutradara mengarahkan pemain, meletakkan latar belakang, properti dan semua elemen menjadi satu kesatuan untuk menciptakan harmoni yang indah sesuai dengan cerita yang ada. Penempatan dan pergerakan pemain di dalamnya harus direncanakan untuk memperoleh reaksi penonton yang diharapkan. Dengan melakukan pengaturan elemen secara baik dapat menimbulkan kesan statis, dinamis, dan sangat berbeda
Selain faktor-faktor dasar dalam sinematografi, gaya seorang sutradara akan mempengaruhi hasil akhir sebuah produk sinematik. Dengan menerapkan gaya seorang sutradara maka hasil produk sinematik akan jauh lebih menarik. Banyak pengemar permainan tahu permainan semacam Mario Bros yang sangat terkenal dan ada beberapa versi permainan serta dilakukan banyak penelitian berkaitan dengan permaian ini (Summervile, Marino, Snodgrass, Ontanon \& Lellis 2017) (Karakovsiy dan Togelius 2012). Permainan Mario Bros asli merupakan permainan sederhana dengan sistem side scroll dan penempatan posisi kamera secara statis berada di sebelah kanan pemain. Bayangkan bilamana dalam permainan yang sederhana ini dapat dipasang sebuah agen penempatan posisi kamera berdasarkan sebuah gaya sutradara maka permainan mario bros akan berbeda nuansanya. Bayangkan bilamana permainan ini dipasang mesin pemainan $R P G$ seperti Zelda atau mesin kamera 3D real time untuk permainan aksi dan petualangan semacam Assassin Creed (Miller 2015) (Davies 2015). Hasilnya adalah nuansa permainan yang berbeda 180 derajat dengan permainan aslinya.

\section{FUZZY LOGIC}

Fuzzy logic telah banyak digunakan dalam penelitian di bidang otomasi dan industri manufaktur. Pada penelitian ini, fuzzy logic digunakan untuk menentukan berbagai macam variasi penempatan posisi kamera. Beberapa penelitian menggunakan metode semacam behavior tree bahkan machine learning untuk mengubah posisi penempatan kamera, tetapi penelitian ini menggunakan fuzzy karena adanya persamaan antara bahasa di dunia sinematografi dan bahasa fuzzy. Logika fuzzy dengan metode mamdani digunakan karena dapat mencerminkan keadaan sesuai dengan kenyataan kehidupan sebenarnya (Adhimantoro 2014) (Wajiansjah, Bramanto dan Nur 2018).

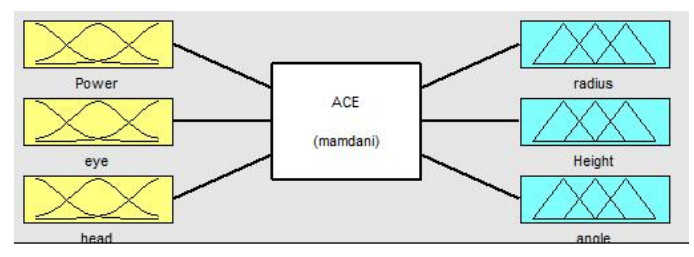

Gambar 4. Blok Sistem Logika Fuzzy

Dengan menggunakan logika fuzzy, setiap virtual kamera dapat merubah variasi penempatan kamera bedasarkan beberapa variabel input sesuai dengan variasi penempatan kamera yang telah didesain. Logika fuzzy yang digunakan adalah Mamdani. Pada penelitian ini digunakan inferensi mamdami karena kesuaian akuisi data dengan output fuzzy yang tidak linier atau konstan seperti inferensi 
sugeno. Dapat dilihat pada tabel 2 output tidak linier. Dengan metode ini penempatan kamera dapat dihasilkan dari rule-rule yang ada. Rule ini akan digunakan oleh sinematografer untuk menghasilkan gambar yang sesuai dengan style yang diinginkan.

Seperti yang dilihat pada Gambar 4, terdapat 3 parameter input untuk sistem dan 3 variabel output yang digunakan pada sistem fuzzy

- Input parameter

\section{- Power}

Power adalah berapa banyak energi yang digunakan untuk melakukan sebuah aksi. Energi yang digunakan untuk lari akan lebih besar daripada energi untuk berjalan atau bahkan diam. Gambar 5 merupakan fungsi keanggotaan untuk power.

- Eye View Point

Eye View Point adalah arah mata melihat. Posisi arah mata dapat melihat ke atas atau ke bawah. Gambar 6 merupakan fungsi keanggotaan untuk Eye View Point.

- Head Movement

Head movement adalah arah pergerakan kemana kepala berputar. Yang mana kepala dapat berputar ke kanan atau ke kiri. Gambar 7 merupakan fungsi keanggotaan untuk Head Movement.

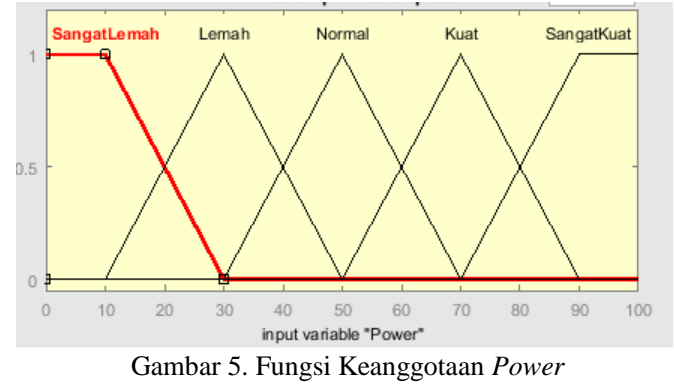

Pemilihan tipe keanggotaan apakah berupa trapesium atau berupa segitiga dikarena koefisien data yang sesuai berdasarkan proses akuisisi pengetahuan dari pakar.

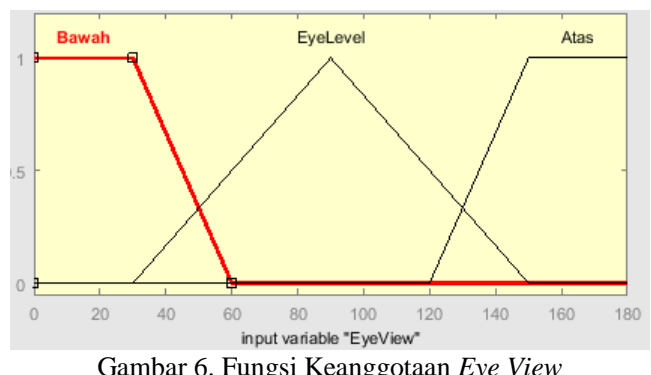

Gambar 6. Fungsi Keanggotaan Eye View

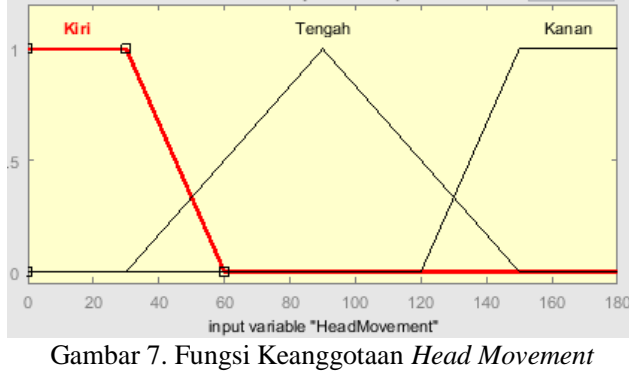

Tabel 1. Fungsi Keanggotan Input Fuzzy

\begin{tabular}{|c|c|c|c|c|}
\hline \multirow{2}{*}{$\begin{array}{c}\text { Variabel } \\
\text { Input }\end{array}$} & \multicolumn{4}{|c|}{ Fungsi Keanggotaan } \\
\hline & Range & MF & Tipe & Control \\
\hline \multirow[t]{5}{*}{ Power } & $0 . .100$ & $\begin{array}{l}\text { Sangat } \\
\text { Lemah }\end{array}$ & $* *$ & {$[0,0,10,30]$} \\
\hline & & Lemah & * & {$[10,30,50]$} \\
\hline & & Normal & $*$ & {$[30,50,70]$} \\
\hline & & Kuat & $*$ & {$[50,70,90]$} \\
\hline & & $\begin{array}{c}\text { Sangat } \\
\text { Kuat }\end{array}$ & $* *$ & {$[70,90,100,100]$} \\
\hline \multirow[t]{3}{*}{ Eye View } & $0 . .180$ & Bawah & $* *$ & {$[0,0,30,60]$} \\
\hline & & $\begin{array}{l}\text { Eye } \\
\text { Level }\end{array}$ & $*$ & {$[30,90,150]$} \\
\hline & & Atas & $* *$ & {$[120,150,180,180]$} \\
\hline Head & $0 . .180$ & Kiri & $* *$ & {$[0,0,30,60]$} \\
\hline \multirow[t]{2}{*}{ Movement } & & Tengah & $*$ & {$[30,90,150]$} \\
\hline & & Kanan & $* *$ & {$[120,150,180,180]$} \\
\hline
\end{tabular}

** Fungsi Keanggotaan Trapesium

* Fungsi Keanggotaan Segitiga

Tabel 1 merupakan tabel fungsi keanggotan input fuzzy. Pada tabel 1 terdapat 3 buah variabel input yang berupa bilangan tegas. Nilai ini didapatkan dari aksi pada simulasi permainan yang dirancang. Fungsi keanggotaan input fuzzy dari sistem yang dirancang ada 2 tipe yaitu trapesium dan segitiga. Gambar 8 akan menunjukkan fungsi keanggotaan trapesium dimana untuk membentuk fungsi tersebut dibutuhkan empat buah kontrol yaitu $a, b, c$ dan d. Sedangkan pada fungsi keanggotaan segitiga membutuhkan tiga buah kontrol yaitu a,b dan c seperti tampak pada Gambar 9.

$\mu(Z)$

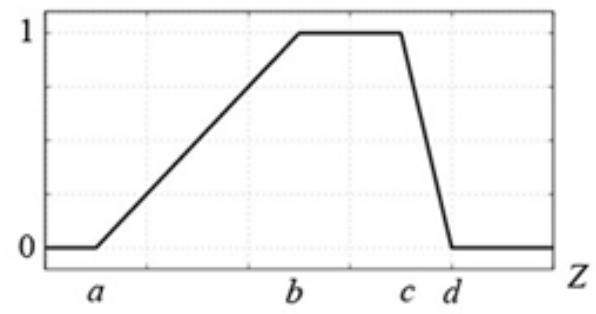

Gambar 8. Fungsi Keanggotaan Trapesium $\mu(Z)$

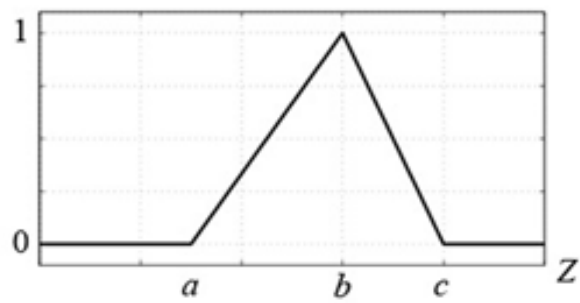

Gambar 9. Fungsi Keanggotaan Segitiga 
Tampak pada tabel 1 Pada eye view dan head movement digunakan range $0 . .180$ (dalam derajat) karena keterbatasan pergerakan kepala manusia yaitu maksimal 90 derajat dan -90 derajat untuk pergerakan sebaliknya. Sudut 0 derajat merupakan posisi kepala normal. Variabel input adalah power dimana range nya antara $0 \mathrm{~s} / \mathrm{d} 100$.

\begin{tabular}{ccccc}
\multicolumn{4}{c}{ Tabel 2. Fungsi Keanggotan Output Fuzzy } \\
\hline Variabel & \multicolumn{4}{c}{ Fungsi Keanggotaan } \\
\cline { 2 - 5 } Output & Range & MF & Tipe & \multicolumn{1}{c}{ Control } \\
\hline Radius & $0 . .100$ & Close Up & $* *$ & {$[0,0,10,40]$} \\
& & Medium & $*$ & {$[20,50,80]$} \\
& & Long & $* *$ & {$[60,90,100,100]$} \\
Height & \multirow{2}{*}{$0 . .180$} & Frog & $* *$ & {$[0,0,15,30]$} \\
& & Low & $*$ & {$[20,55,90]$} \\
& & Eye & $*$ & {$[50,85,120]$} \\
& & High & $*$ & {$[90,125,160]$} \\
Angle & \multirow{2}{*}{$0 . .180$} & Bird & $* *$ & {$[150,165,180,180]$} \\
& & Kiri & $* *$ & {$[0,0,30,60]$} \\
& & Tengah & $*$ & {$[30,90,150]$} \\
& & Kanan & $* *$ & {$[120,150,180,180]$} \\
\hline
\end{tabular}

** Fungsi Keanggotaan Trapezoida

* Fungsi Keanggotaan Triangular

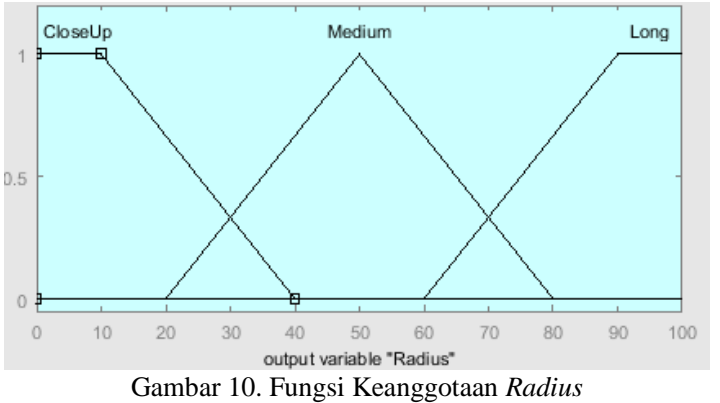

Gambar 10. Fungsi Keanggotaan Radius
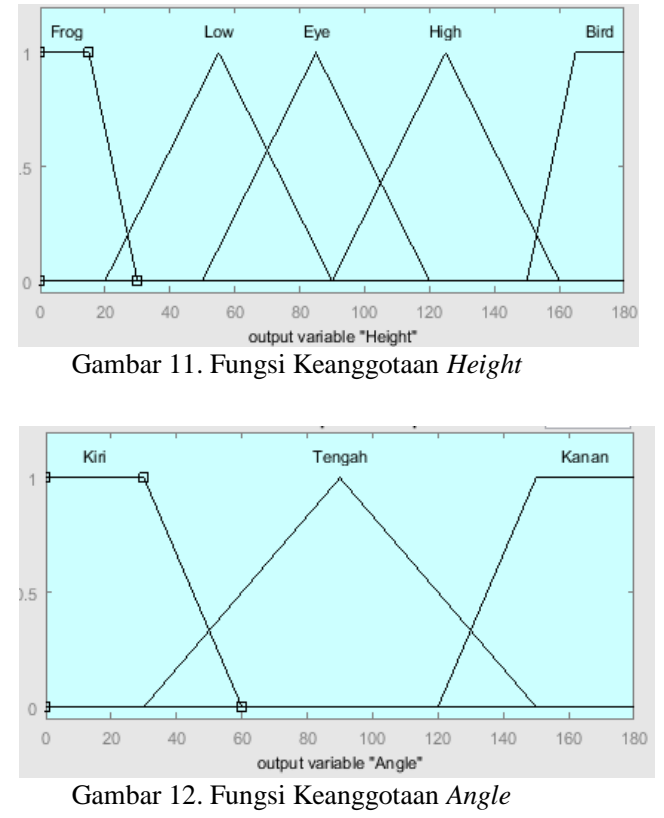

- Output result

- Radius

Radius adalah jarak antara karakter dengan kamera. Nilai dari radius berhubungan dengan camera angle (close up shot, medium shot dan long shot). Nilai dari radius berkisar antara 0-100. Nilai ini berhubungan dengan dimensi jarak dalam lingkungan 3D. Terlihat pada Gambar 10 adalah fungsi keanggotaan untuk radius.

- Height

Height adalah sudut ketinggian kamera melihat ke karakter. Sudut ketinggian kamera dapat dibagi lagi menjadi frog eye, low angle shot, eye level shot, high angle shot dan bird view. Nilai dari height antara 0-180 derajat. Sedangkan nilai untuk eye level shot yaitu posisi normal sebesar 85 derajat. Gambar 11 merupakan fungsi keanggotaan untuk Height.

- Angle

Angle adalah derajat antara karakter dan kamera yang menentukan posisi kamera terletak di depan, belakang, kanan atau kiri karakter. Dalam penelitian ini posisi kamera di belakang karakter tidak digunakan. Dalam dunia fotografi nama pengambilan gambar ini disebut left shot, center shot dan right shot. Nilai dari angle ini antara 0-180 derajat. Nilai dari center shoot yaitu pengambilan tepat di depan karakter adalah sebesar 90 derajat. Gambar 12 merupakan fungsi keanggotaan untuk angle.

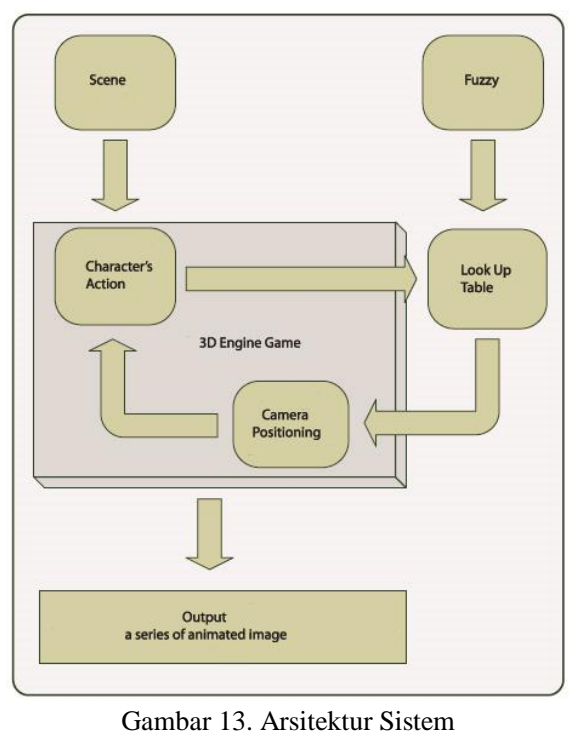

Gambaran umum sistem dalam penelitian ini dapat dilihat pada Gambar 13. Aturan-aturan yang dimasukan dalam sistem fuzzy ini adalah pengetahuan yang didapat dari kegiatan studi lapangan dan wawancara dengan sekelompok fotografer yang pakar di bidang sinematik. Hasil wawancara ini dibagi menjadi dua kelompok yang akan dianggap sebagai dua gaya sutradara berbeda. 
Tabel 3. Point of View Kamera Depan

\begin{tabular}{lccc}
\hline \multicolumn{1}{c}{ Aksi } & Radius & Height & Angle \\
\hline Tunduk & Medium Shot & Eye Level & Left of Right \\
Berdiri & Medium Shot & Eye Level & Center \\
Menengadah & Close up & High Angle & Left of Right \\
Toleh Kiri & Medium Shot & Eye Level & Right \\
Toleh Kanan & Medium Shot & Eye Level & Left \\
Jalan & Medium Shot & Eye Level & Center \\
Lari & Long Shot & Low Angle & Left of Right \\
Melompat & Long Shot & Eye Level & Center \\
Membungkuk & Medium Shot & Eye Level & Left of Right \\
\hline
\end{tabular}

Tabel 3 adalah penempatan posisi kamera yang bagus dari depan karakter dan Tabel 4 adalah penempatan posisi kamera yang bagus dari pengambilan samping. Dari kedua tabel tampak dilihat pada aksi yang sama pengambilan gambar dengan gaya yang berbeda.

Seperti yang terlihat pada Gambar 13, logika fuzzy akan menghasilkan aturan-aturan dari perilaku kamera yang disebut dengan "look up table". Look up table ini akan digunakan sistem ACE untuk menempatkan posisi kamera berdasarkan kejadian atau kegiatan yang sedang dilakukan karakter. Kemudian mesin 3D akan menghasilkan sekelompok gambar bergerak berdasarkan karakter dan posisi kamera.
Untuk membuat sebuah animasi atau permainan komputer maka pergerakan karakter harus dibuat senyata mungkin. Pada Gambar 15a terlihat batasan nyata dari pergerakan kepala manusia untuk menengadah ke atas dan tunduk ke bawah. Kepala manusia normalnya dapat bergerak ke atas dan bawah sekitar 0-180 derajat dengan acuan 90 derajat sebagai kepala posisi normal. Begitu pula dengan pergerakan kepala manusia untuk menoleh ke kanan dan kiri yang dapat dilihat pada Gambar 15b. Akan tampak tidak nyata bilamana kepala manusia dapat berputar lebih dari sudut normal.

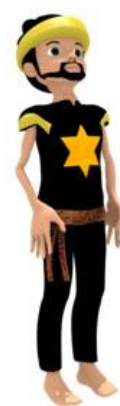

(a) Up and Down

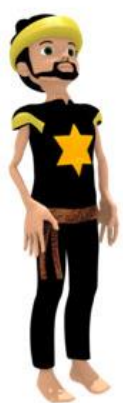

(b) Left And Right
Gambar 15. Pergerakan Kepala Manusia

Gambar 16 merupakan area penempatan posisi kamera virtual. Area penempatan posisi kamera virtual adalah separuh spherical, kamera virtual akan ditempatkan pada area yang berwarna yang lebih gelap. Terdapat dua jenis gaya penempatan posisi kamera yaitu penempatan posisi kamera di depan karakter dan penempatan posisi kamera di sebelah kiri karakter.
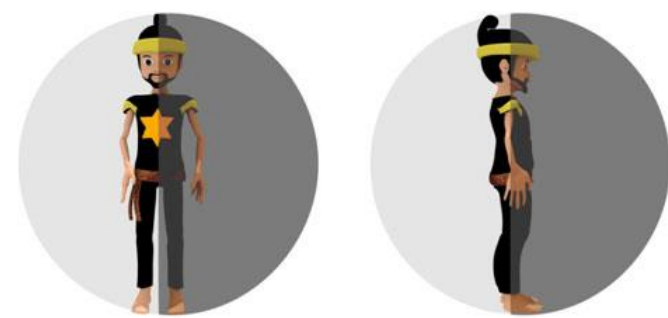

Gambar 16. Area Pengerakan dan Penempatan Kamera

\section{HASIL PERCOBAAN}

Pada penelitian ini, animasi untuk permainan akan dibuat meggunakan 3D engine Blender dan untuk pembuatan rule fuzzy menggunakan Matlab. Karakter yang digunakan adalah "Gatot Kaca" seperti yang dapat dilihat pada Gambar 17. Gatot kaca adalah salah karakter utama wayang di Indonesia. Karakter ini sangat tekenal dalam cerita fiksi mahabarata. Karakter ini telah di desain agar sesuai dengan kebudayaan modern. 


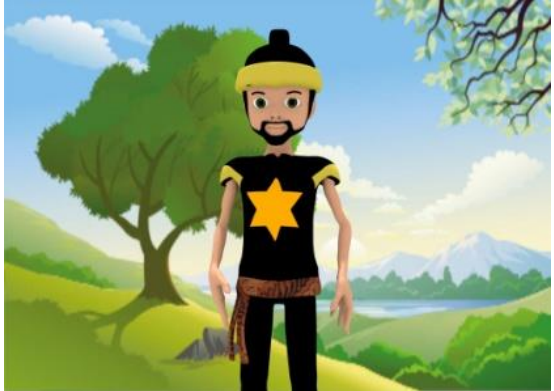

Gambar 17. Karakter

Untuk percobaan dalam penelitian ini digunakan 3 buah kamera virtual untuk animasi. Kamera virtual pertama adalah sebuah statis kamera yang akan menggunakan sudut pengambilan point of view orang ketiga. Penempatan posisi kamera ini berada di belakang punggung karakter utama seolaholah diambil dari sudut mata orang ketiga. Sedangkan kamera virtual kedua dan ketiga akan menggunakan kamera dengan penempatan posisi kamera dinamis secara otomatis, di mana perilaku untuk kamera virtual kedua dan ketiga memiliki gaya sutradara yang berbeda. Kamera virtual kedua ditempatkan di depan karakter utama, sedangkan kamera virtual ketiga ditempatkan di sebelah kanan karakter. Pada penelitian ini akan ditampilkan visualisasi atau hasil tangkapan kamera virtual.

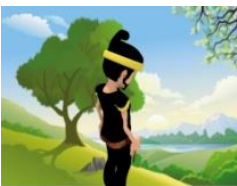

(a) tunduk

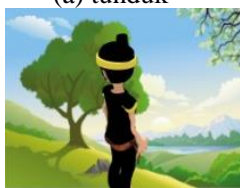

(d) toleh kiri

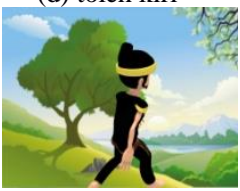

(g) lari

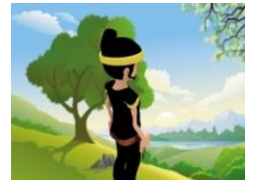

(b) berdiri

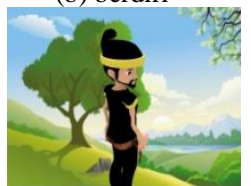

(e) toleh kanan

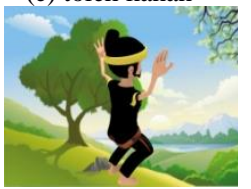

(h) melompat

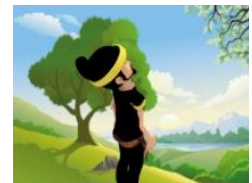

(c) menengadah

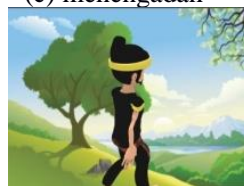

(f) jalan

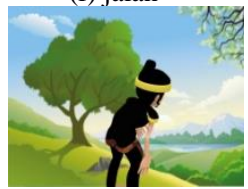

(i) membungkuk
Gambar 18. Hasil Tangkapan Kamera Pertama

Tabel 5. Penempatan Posisi Kamera Kedua

\begin{tabular}{lccc}
\multicolumn{1}{c}{ Aksi } & Radius & Height & Angle \\
\hline Tunduk & 50.0 & 85.0 & 22.9 \\
Berdiri & 50.0 & 85.0 & 90.0 \\
Menengadah & 13.7 & 125.0 & 22.9 \\
Toleh Kiri & 50.0 & 85.0 & 154.0 \\
Toleh Kanan & 50.0 & 85.0 & 26.0 \\
Jalan & 63.7 & 70.0 & 67.6 \\
Lari & 65.1 & 70.0 & 51.9 \\
Melompat & 85.6 & 55.0 & 90.0 \\
Membungkuk & 62.1 & 70.0 & 27.7 \\
\hline
\end{tabular}

Tampak pada Gambar 18 adalah hasil perekaman posisi kamera virtual pertama. Terlihat pada gambar untuk setiap adegan apa pun posisi kamera selalu statis dari sudut mata orang ketiga yang terletak di belakang kanan karakter utama percobaan.

Seperti yang dilihat pada Tabel 5 adalah hasil penempatan posisi kamera virtual kedua untuk beberapa aksi. Untuk adegan kepala menunduk akan menghasilkan nilai output radius $=50$, height $=85.0$ dan angle $=22.9$. Hal tersebut mempunyai arti bahwa untuk adegan kepala menunduk maka kamera virtual kedua akan melakukan pengambilan gambar dengan aturan medium shot, eye level view dan left shot. Hal ini sudah sesuai dengan hasil penempatan posisi kamera kelompok pertama pada Tabel 3 yaitu perekaman dilakukan secara medium shot sejajar mata dan boleh di sebelah kiri atau kanan. Gambar 19a adalah hasil pengambilan adegan kepala menunduk menggunakan kamera virtual kedua. Terlihat bahwa kamera mengambil gambar sejajar posisi mata dengan jarak menengah dan diambil dari sisi kiri. Gambar 19 menunjukkan hasil perekaman kamera virtual berdasarkan sebuah gaya tersendiri. Tampak bahwa untuk setiap aksi, posisi kamera berbeda dengan posisi pada kamera virtual pertama.

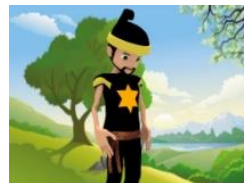

(a) tunduk

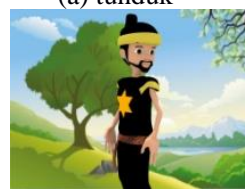

(d) toleh kiri

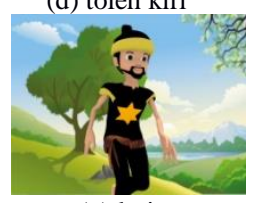

(g) lari

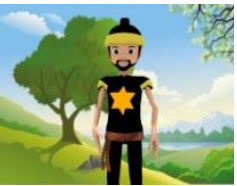

(b) berdiri

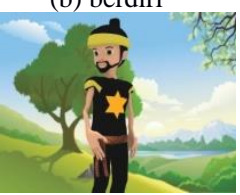

(e) toleh kanan

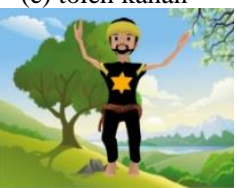

(h) melompat
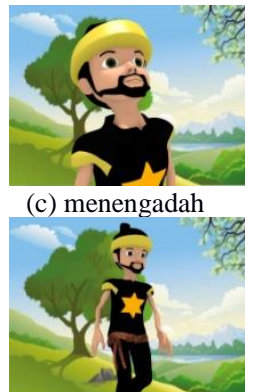

(f) jalan

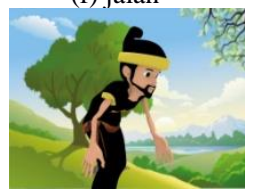

(i) membungkuk
Gambar 19. Hasil Tangkapan Kamera Kedua

Tabel 6. Penempatan Posisi Kamera Ketiga

\begin{tabular}{lccc}
\hline \multicolumn{1}{c}{ Aksi } & Radius & Height & Angle \\
\hline Tunduk & 40.0 & 85.0 & 157.0 \\
Berdiri & 50.0 & 85.0 & 90.0 \\
Menengadah & 50.0 & 85.0 & 90.0 \\
Toleh Kiri & 16.3 & 25.0 & 154.0 \\
Toleh Kanan & 50.0 & 55.0 & 154.0 \\
Jalan & 63.7 & 70.0 & 112.0 \\
Lari & 85.2 & 70.0 & 112.0 \\
Melompat & 85.6 & 85.0 & 23.8 \\
Membungkuk & 82.1 & 70.0 & 152.0
\end{tabular}

Seperti yang dilihat pada Tabel 6 adalah hasil penempatan posisi kamera virtual ketiga untuk beberapa aksi dengan menggunakan gaya kelompok fotografer kedua pada Tabel 4 yang berbeda dengan kamera virtual pertama dan kedua. Hasil yang didapatkan untuk aksi kepala menunduk adalah radius $=40$, height $=85.0$ dan angle $=127$. Hal ini berarti untuk aksi kamera menunduk kamera virtual akan melakukan pengambilan gambar dengan 
medium shot tetapi lebih close up, eye level, dan right shot. Hal ini sesuai dengan pengamatan kelompok fotografer yang tercatat pada tabel 4 yaitu perekaman secara medium shot sejajar mata dan dari sisi kanan. Seperti yang dilihat pada Gambar 20a adalah hasil pengambilan adegan kepala menunduk dengan menggunakan kamera virtual ketiga. Tampak pada gambar kamera virtual karakter dari jarak medium agak ke depan posisi sejajar mata dan di sebelah sisi kanan. Sedangkan Gambar 20 menunjukkan visualisasi perekaman data kamera virtual ketiga untuk setiap aksi.

Kamera pertama adalah kamera statis posisi nya yaitu point of view third person sehingga pengambilan gambar akan selalu mengambil di belakang samping punggung karakter apapun aksi yang sedang dilakukan karakter. Posisi kamera pertama ini digunakan untuk referensi benchmarking. Sedangkan dua kamera lainnya akan mendapatkan sudut pandang yang berbeda tergantung dari aksi yang dilakukan karakter. Tampak bahwa dengan gaya yang berbeda maka penempatan posisi kamera akan berbeda dan memberikan nuansa yang berbeda.

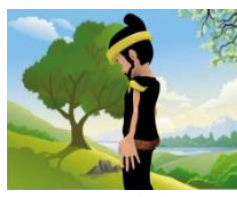

(a) tunduk

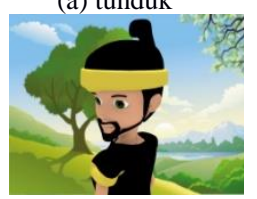

(d) toleh kiri

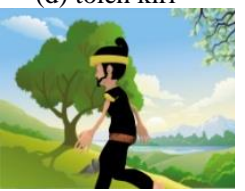

(g) lari

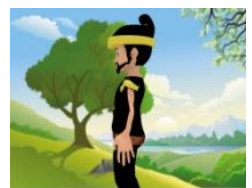

(b) berdiri
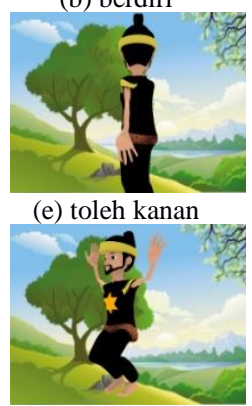

(h) melompat

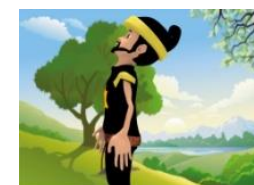

(c) menengadah

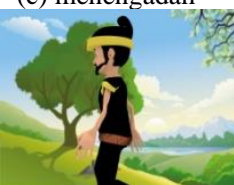

(f) jalan

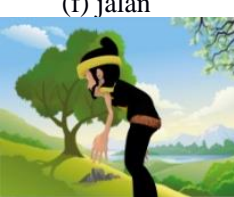

(i) membungkuk
Gambar 20. Hasil Tangkapan Kamera Ketiga

\section{KESIMPULAN DAN SARAN}

Dalam penelitian ini, telah dibahas kemungkinan untuk menempatkan kamera virtual berdasarkan gaya sutradara dengan menggunakan pendekatan berbasis logika fuzzy. Logika fuzzy digunakan karena memiliki persamaan bahasa linguistik fuzzy dan bahasa dalam dunia sinematografi.

Berdasarkan hasil percobaan di penelitian ini, dapat dilihat bahwa logika fuzzy berhasil digunakan untuk mewakili perilaku kamera virtual berdasarkan gaya seorang sutradara. Setiap kamera akan memiliki sudut pandang yang berbeda tergantung dari action yang sedang dilakukan. Hasil keluaran ini sudah divalidasi dan diterima oleh sekelompok fotografer yang memang berkecimpung dalam dunia sinematografi sesuai dengan tabel 3 dan tabel 4 .

Untuk penelitian selanjutnya, dapat ditambahkan beberapa parameter input dan menambahkan perilaku lain yang dapat diimplementasikan dalam sistem penempatan posisi kamera misalkan penempatan posisi kamera tidak hanya berbentuk separuh sperical melainkan dapat secara 360 derajat untuk ketiga sumbu. Dan adanya peningkatan bagi sistemnya untuk dapat memilih salah satu dari beberapa dari sudut pandang kamera yang sesuai. Sistem akan dapat memilih sudut terbaik untuk aksi yang sedang terjadi.

\section{UCAPAN TERIMA KASIH}

Ucapan terima kasih diberikan kepada temanteman mahasiswa di Departemen Teknik Elektro, Fakultas Teknologi Elektro, Institut Teknologi Sepuluh November atas bantuan dan saran-saran yang diberikan dalam menyelesaikan makalah penelitian ini. Terima kasih juga diberikan kepada rekan-rekan komunitas fotografer dalam bantuannya untuk mempersiapkan data yang digunakan dalam penelitian ini

\section{DAFTAR PUSTAKA}

HANCOCK,H. dan INGRAM, I., 2007. Machinima For Dummies. Willey Publishing.

HART,J., 2007. The Art of The Story Board : A Filmmaker's Introduction. 2nd ed. Focal Press.

RANON, R., CHITTARO, L., \& BUTTUSI, F., 2015. Automatic Camera Control Meets Emergency Situations : An Application to Aviation Safety. , Computer And Graphics, Vol 48, pp . 23-34.

BENNETT, J., dan CARTER, C.P., 2014. Adopting Virtual Production For Animated Filmaking. 7th Annual Internasional Conference on Computer Games, Multimedia and Allied Techology (CGAT) Singapore

HU, W. dan ZHANG, X., 2012, A Semiautomatic Control Techique for Machinima Virtual Camera. Internasional Conference on Computer Science and Electronics Engineering (ICCSEE), Vol 1., pp. 112-115

PRIMA, D., JAVA, F., SURYANTO, E., \& HARIADI, M., 2013. Secondary Camera Placement in Machinema Using Behavior Tree. Internasional Conference on Quality In Reseach, pp. 94-98

JUNAEDI, H., HARIADI, M., dan PURNAMA, I.K.E., 2013. Multi Agent With Multi Behavior Based On Particle Swar, Optimization (PSO) for Crowd Movement in Fire Evacuation. 4th Internation 
Conference on Intelligent Control and Information Processing (ICICIP), pp. 366372

BURELli, P., GASPERO, L., ERMETICI, A., \& RANON, R.,. 2008. Virtual Camera Composition With Particle Swarm Optimization. Smart Graphics., pp. 130141.

BARRY, W. dan ROSS, B.J,. 2014. Virtual Photography using Multi Objective Particle Swarm Optimization. Proceeding of the 2014 Annual Conference on Genetic and Evolutionary Computation GECCO,. New York USA pp. 285-292

PRIMA, D., HARIADI, M., PURNAMA, I.K.E, dan USAGAWA, T. 2016. Virtual Camera Movement With Particle Swarm Optimization and Local Regression. Internasional Review on Computer and Software (IRECOS),. Vol 11, No. 9

JAAFAR, J., dan MCKENZIE, E., 2006. Behaviour Coordination of Virtual Agent Navigation using Fuzzy Logic. IEEE Internation Conference on Fuzzy System. Pp. 11391145.

NICOLAS, H., RALF, H. dan THOMAS, S., 2001. A Camera Engine for Computer Games : Managing The Trade Off Between Constrain Satisfaction and Frame Coherence. Computer Graphics Forums. Vol 20,. No. 3, pp. 174-183

MASCELLI, J.V., 1965. The Fives Cinematography : Motion Picture Filming Techniques. Silman James Press

ARIJON, D.. 1976. Grammar of The Film Language. Hasting House

BROWN, B., 2012. Cinematography Theory and Practice : Image Making for Cinematographer. Directors and Videographers. Focal Press

SUMMERVILE, A., MARINO, J.R., ONTANON, S. Dan LELIS, L.H.S., 2017. Understanding Mario : An Evaluation of Design Metrics for Platformers. 12th Internation Conference on The Foundation of Digital Games,. New York-USA. Pp 8:1$8: 10$.

KARAKOVSIY, S., dan TOGELIUS, J. 2012. The Mario AI Benchmark and Competition. IEEE Transaction on Computational Intelligence and AI in Games. Vol 4. pp 5567.

MILLER, M. 2015. Assasin's Creed : The Complete Visual History. Insight Edition

DAVIES, P. 2014. The Art of Assasin's Creed Unity. UK : Titan Books
ADHIMANTORO, S., 2014. Mengetahui Tingkat Kematangan Buah Dengan Ultrasonik Menggunakan Logika Fuzzy". Jurnal Nasional Tekok Elektro dan Teknologi Informasi. Vol 3, No. 1. pp. 63-68.

WAJIANSYAH, A., BRAMANTO, A. dan NUR, S.S. 2018. Implementasi Fuzzy Logic Pada Robot Line Follower. Jurnal Teknologi Informasi dan Ilmu Komputer. Vol 5, No. 4. pp.395-402. 